\title{
A unique insert in the genomes of high-risk human papillomaviruses with a predicted dual role in conferring oncogenic risk [version 1; peer review: 2 approved]
}

\author{
Noam Auslander, Yuri I. Wolf, Svetlana A. Shabalina, Eugene V. Koonin (iD)
}

National Center for Biotechnology Information, National Institutes of Health, USA, Bethesda, Maryland, 20814, USA

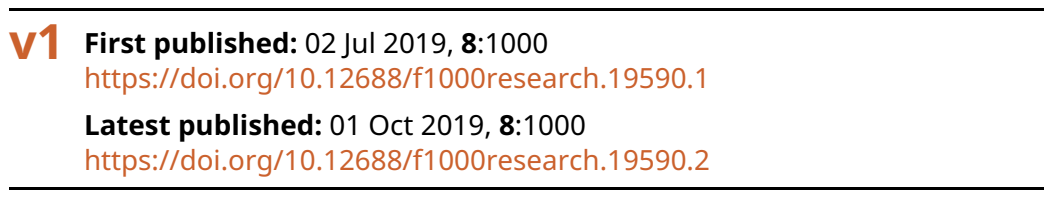

\section{Abstract}

The differences between high risk and low risk human papillomaviruses (HR-HPV and LR-HPV, respectively) that contribute to the tumorigenic potential of HR-HPV are not well understood but can be expected to involve the HPV oncoproteins, E6 and E7. We combine genome comparison and machine learning techniques to identify a previously unnoticed insert near the 3 '-end of the E6 oncoprotein gene that is unique to HR-HPV. Analysis of the insert sequence suggests that it exerts a dual effect, by creating a PDZ domain-binding motif at the C-terminus of E6 as well as eliminating the overlap between the E6 and E7 coding regions in HR-HPV. We show that as a result, the insert might enable coupled termination-reinitiation of the E6 and E7 genes, supported by motifs complementary to the human $18 \mathrm{~S}$ rRNA. We hypothesize that the added functionality of E6 and positive regulation of $E 7$ expression jointly account for the tumorigenic potential of HR-HPV.

\section{Keywords}

Papillomaviruses, cervical cancer, oncogenic risk, translation terminatio-reinitiation, machine learning

Open Peer Review
Approval Status
version 2
(revision)
01 Oct 2019
02 Jul 2019
1. Alison McBride 1
Allergy and Infectious Diseases (NIAID),
Bethesda, USA
2. Elizabeth A. White, University of
Pennsylvania Perelman School of Medicine,
Philadelphia, USA
Any reports and responses or comments on the
article can be found at the end of the article.


Corresponding authors: Noam Auslander (noamaus@gmail.com), Eugene V. Koonin (koonin@ncbi.nlm.nih.gov)

Author roles: Auslander N: Conceptualization, Data Curation, Formal Analysis, Investigation, Methodology, Software, Writing - Original Draft Preparation; Wolf YI: Investigation, Methodology; Shabalina SA: Formal Analysis, Methodology; Koonin EV: Conceptualization, Investigation, Supervision, Writing - Review \& Editing

Competing interests: No competing interests were disclosed.

Grant information: This work was supported by U.S. Department of Health and Human Services (Intramural funds). The funders had no role in study design, data collection and analysis, decision to publish, or preparation of the manuscript.

Copyright: ( 2019 Auslander $\mathrm{N}$ et al. This is an open access article distributed under the terms of the Creative Commons Attribution License, which permits unrestricted use, distribution, and reproduction in any medium, provided the original work is properly cited. The author(s) is/are employees of the US Government and therefore domestic copyright protection in USA does not apply to this work. The work may be protected under the copyright laws of other jurisdictions when used in those jurisdictions.

How to cite this article: Auslander N, Wolf YI, Shabalina SA and Koonin EV. A unique insert in the genomes of high-risk human papillomaviruses with a predicted dual role in conferring oncogenic risk [version 1; peer review: 2 approved] F1000Research 2019, 8:1000 https://doi.org/10.12688/f1000research.19590.1

First published: $02 \mathrm{Jul}$ 2019, 8:1000 https://doi.org/10.12688/f1000research.19590.1 


\section{Introduction}

Persistent infections with carcinogenic human papillomaviruses (HPVs) are the main cause of cervical neoplasia and cancer, with over $99 \%$ of the cervical lesions containing HPV sequences $^{1-3}$. More than $160 \mathrm{HPV}$ types have been characterized ${ }^{4}$, of which approximately a third are predominantly detected in the cervical epithelium and belong to the Alphapapillomavirus genus $^{5,6}$. The viruses of this genus are further grouped into high-risk (HR) and low-risk (LR) HPV types based on their association with cervical cancer and pre-cancerous lesions ${ }^{7,8}$. Most of the HR-HPV variants belong to the Human papillomavirus 16 (alpha-9) or Human papillomavirus 18 (alpha-7) species groups 9

Phylogenetic trees constructed from alignments of complete HPV genomes cluster all oncogenic types together, suggesting a common ancestor for the HR-HPVs. However, in separate trees built from different regions of the genome, the carcinogenic potential co-segregates with the early but not with the late genes $^{10,11}$. The early HPV proteins E6 and E7 have transforming properties $^{12-14}$ and are required for the malignant conversion. The involvement of these proteins in tumorigenesis is thought to stem from their interactions with the tumor suppressors p53 and $\mathrm{pRB}$, respectively, as well as other proteins involved in tumorigenesis $^{14-17}$. Variations in E6 and E7 proteins have been suggested to determine the oncogenic potential of HPV ${ }^{18,19}$ but the potential discriminating features of the oncogenic variants are frequently observed in LR-HPVs as well ${ }^{20-24}$. Currently, the most notable molecular feature that distinguishes HR from LR-HPV is the presence of a PDZ-domain recognition motif at the extreme $\mathrm{C}$ terminus of the HR-E6 oncoprotein, as opposed to LR-E6 ${ }^{25-27}$, enabling interactions with numerous proteins that contain the PDZ domain ${ }^{28-30}$.

Identification of signatures of the HR-HPV genotypes that differentiate them from the majority of alphapapillomaviruses that lack oncogenic potential could help elucidate the genetic basis of the carcinogenic properties of HPVs, thus contributing to a better understanding of the biological mechanisms exploited by the virus to trigger neoplasia. However, at present, genomic determinants of the HPV oncogenic risk are not well understood, and the exact nature of the genetic changes that led to the emergence of the HR-HPV oncogenicity remains unknown.

To better understand HPV carcinogenesis, we revisited the search for specific genomic determinants of HR-HPV types and identified a previously unreported insert of 30 to 60 basepairs (bp) at the 3'-end of the E6 oncoprotein coding region that is present in all HR-HPV types but not in LR-HPV. This insert introduces a new stop codon, separating the nucleotide sequence coding E6 from that coding for E7, eliminating the overlap between E6 and E7 that is characteristic of the LR-HPV types. The insert confers a PDZ binding motif at the end of E6 oncoprotein which is likely important for the oncogenic potentiation. Additionally, it locates the E6 termination codon upstream of and in close proximity to the E7 initiation codon. Furthermore, the insert contains sequences complementary to human 18S rRNA in the regions of hairpins 26 and 27 that are known interactors of $40 \mathrm{~S}$ ribosomal subunits and viral RNAs, specifically involved in IRES binding. The folding of these regions of rRNA complementarity in E6-E7 mRNAs is typically relaxed in the predicted optimal and sub-optimal secondary structures of HR-HPV strains. We hypothesize that the insert into the E6 coding sequence identified here was the primary cause of the emergence of high oncogenic potential alpha-HPV.

\section{Results}

The complete nucleotide sequences and the amino acid sequences of HPV E1, E2, E4, E5, E6, E7, L1 and L2 proteins were collected for all sequenced alpha-HPV strains (Extended data: Table $\mathrm{S}^{31}$ ). We then constructed a global multiple sequence alignment of the whole genome nucleotide sequences and the amino acid sequences alignments for each protein. Maximum likelihood phylogenetic analysis of these alpha-HPVs, based on the complete nucleotide sequence, as well as the amino acid sequences of most early proteins, identified HR-HPV as a clade, whereas phylogenies of E4, E5, L1 and L2 did not support the monophyly of the HR-HPV (Figure 1; Extended data: Figure $\mathrm{S}^{31}$ ), in agreement with previous findings, ${ }^{9,10}$. These observations are compatible with a major role of recombination in the HPV evolution.

We next sought to identify genomic features that might partition alpha-HPV species, in accord with their oncogenic risk, focusing on the E6 and E7 oncogenes.

First, we searched for regions of insertions and deletions within the genome nucleotide sequences of E6 and E7 that might differentiate between the risk groups. Specifically, we identified sequences with high frequency of deletions or insertions that are located within high confidence alignment regions (See Methods for details). We then applied Support Vector Machine (SVM) with a leave-one-out cross-validation, aiming to identify regions that classify HPV strains based on their oncogenic risk. This approach resulted in the identification of genomic regions that separated HR-HPV from LR-HPV with high accuracy (over 0.75, with statistical significance; see Methods). Among these, we found one prominent insert (approximately 30-60 nucleotides) located within the E6 gene (Figure 2A). We also performed a similar search for regions separating HR-HPV from LR-HPV, using the amino acid sequence of E6 and E7 oncoproteins. For the purpose of classification, we coded the amino acids with numbers based on their frequencies and the BLOSUM62 $2^{32}$ matrix (see Methods). As expected, the divergent region in E6 was identified from the amino acid sequences as well (Figure 2B). In contrast, we did not find any significant differences in E7 protein sequences between the high risk and low risk HPV strains (Extended data: Figure $\mathrm{S} 2^{31}$ ).

The discriminating region identified in the E6 gene contains an insert with a conserved sequence in all HR-HPV strains. The insert contains an in-frame stop codon for the E6 coding sequence, which eliminates the overlap between the coding sequences of E6 and E7 that is characteristic of the LR-HPV genomes, but results in nearly identical lengths of the E6 proteins in HR and LR-HPV strains albeit with unrelated C-terminal sequences of 
A

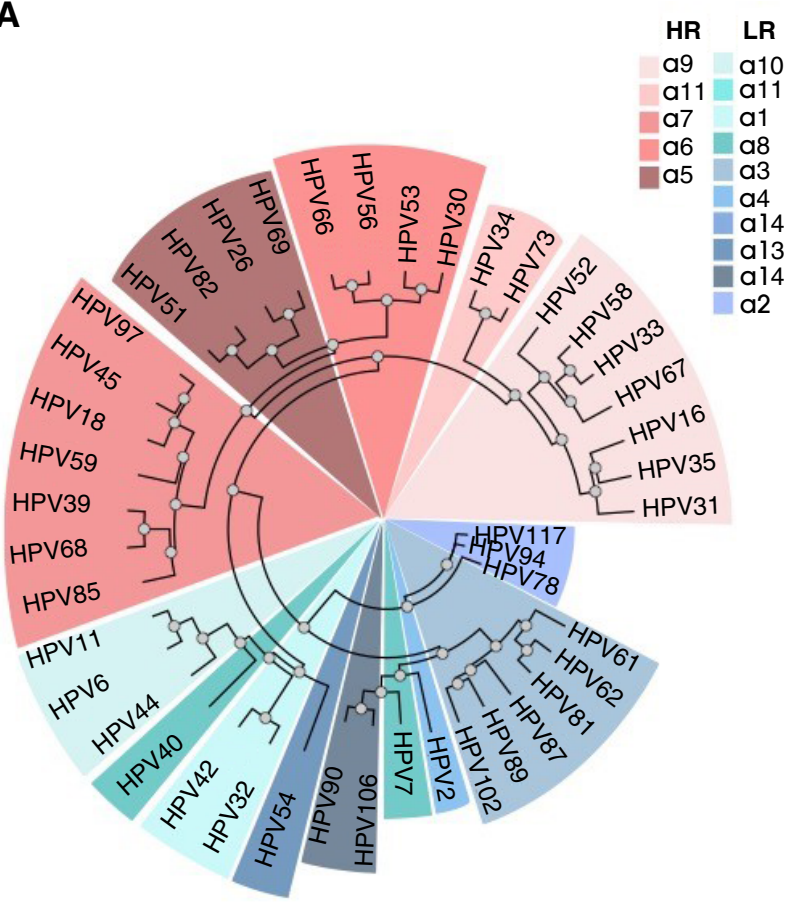

B

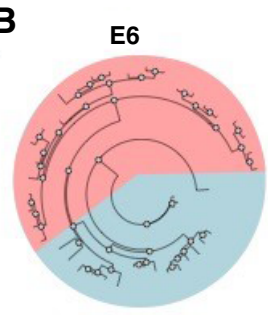

E7

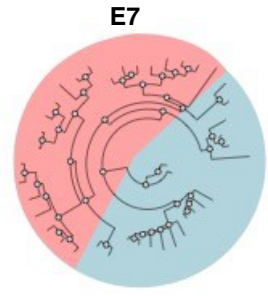

E1

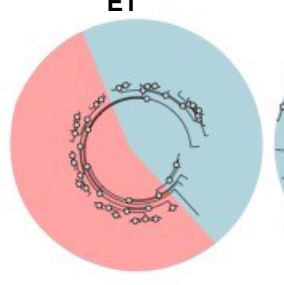

E2

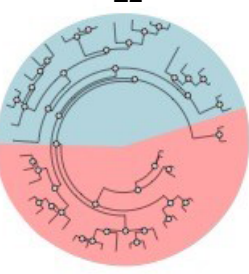

E4

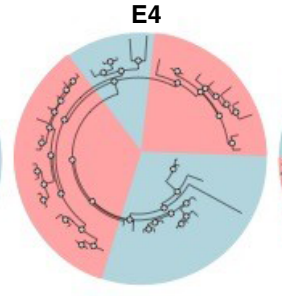

E5

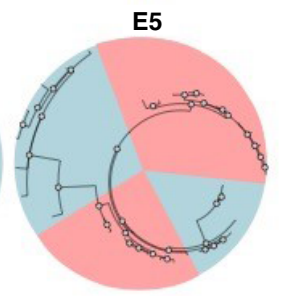

L1

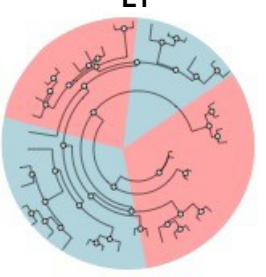

L2

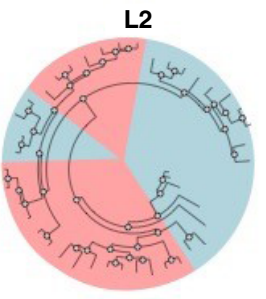

HR LR

Figure 1. Phylogenetic trees of alpha-HPV. (A) Maximum likelihood tree obtained with the whole genome nucleotide sequences alignment of alpha-HPV, colored by the different alpha-class categories. (B) Maximum likelihood trees obtained with alignments of E6, E7, E1, E2, E4, E5, L1 and L2 amino acid sequences of alpha-HPV, colored by the oncogenic risk groups.

8-19 amino acids (Figure 2B). The unique C-terminal sequence of HR-HPV E6 that originates from the insert contains a PDZ domain-binding motif $\mathrm{X}-\mathrm{T}-\mathrm{X}-\mathrm{V} / \mathrm{L}$ at the very C-terminus of E6 in almost all HR-HPVs. Indeed, several PDZ domaincontaining proteins have been identified as binding partners of HR-E6, including hDlg, hScrib, MAGI-1, MAGI-2, MAGI-3, and MUPP1 ${ }^{26,29,30,33-35}$. These interactions that are unique for HR-HPV are likely to be a key contributing factor to HR-HPV induced oncogenesis ${ }^{36}$.

We observed that the sequence similarity between the insert sequences among HR-HPV strains is more pronounced at the nucleotide level than at the amino acid level (See METHODS for details and Extended data: Figure $\mathrm{S}^{31}$ ). Combined with the separation between the coding regions of E6 and E7 resulting from the insertion, and the proximity of E6 stop codon to the E7 start codon, this finding led us to hypothesize that the insert has an additional role as a regulatory region. Furthermore, as E7 has been previously identified as the dominant oncogene $^{37}$, the lack of genomic determinants of HR-HPV within the E7 gene is compatible with the possibility that the insert contains regulatory elements enhancing E7 expression in HR-HPV strains.

In HR-HPV strains, E6 and E7 proteins are translated from a polycistronic pre-mRNA ${ }^{38}$, where translation reinitiation has been suggested as mechanism ${ }^{39-41}$. However, the close proximity of the E6 stop codon to the E7 start codon in HR-HPV (only a few nucleotides separating these codons) could inhibit re-initiation ${ }^{39,40}$. Therefore, it has been suggested that ribosomal reinitiation is enabled through the E6*I splice variant in which the intercistronic distance between the translation termination codon of E6*I and the E7 initiation codon is increased ${ }^{41}$. However, several studies have reported that E7 translation is independent of splicing within the E6 open reading frame ${ }^{40,42,43}$, undermining this interpretation.

Several cases of coupled termination-reinitiation for polycistronic mRNA with proximate stop and start codons are evident for translation of eukaryotic virus genes ${ }^{44-51}$. The efficiency of this process depends on the close proximity of the termination and reinitiation $\operatorname{sites}^{51,52}$, and the presence of motifs complementary to the $18 \mathrm{~S}$ rRNA in the mRNA sequence ${ }^{45,46,51,53}$. Given the proximity of the E6 termination site to the E7 initiation site codon that results from the insertion in the HR-HPV strains conferred by the insert, we investigated the possibility of coupled termination-reinitiaion of E6 and E7 in these strains. Notably, within the inserted sequence in the vicinity of the E7 start codon, we identified two conserved regions that are complementary to the sequences in 18S rRNA hairpins 26 and 27 which are commonly involved in the interactions between ribosomes and virus IRES ${ }^{54}$ (Figure 3A). The first region of complementarity consistently forms an internal loop and a relaxed, unpaired structure in the predicted optimal and sub-optimal E6-E7 mRNA 


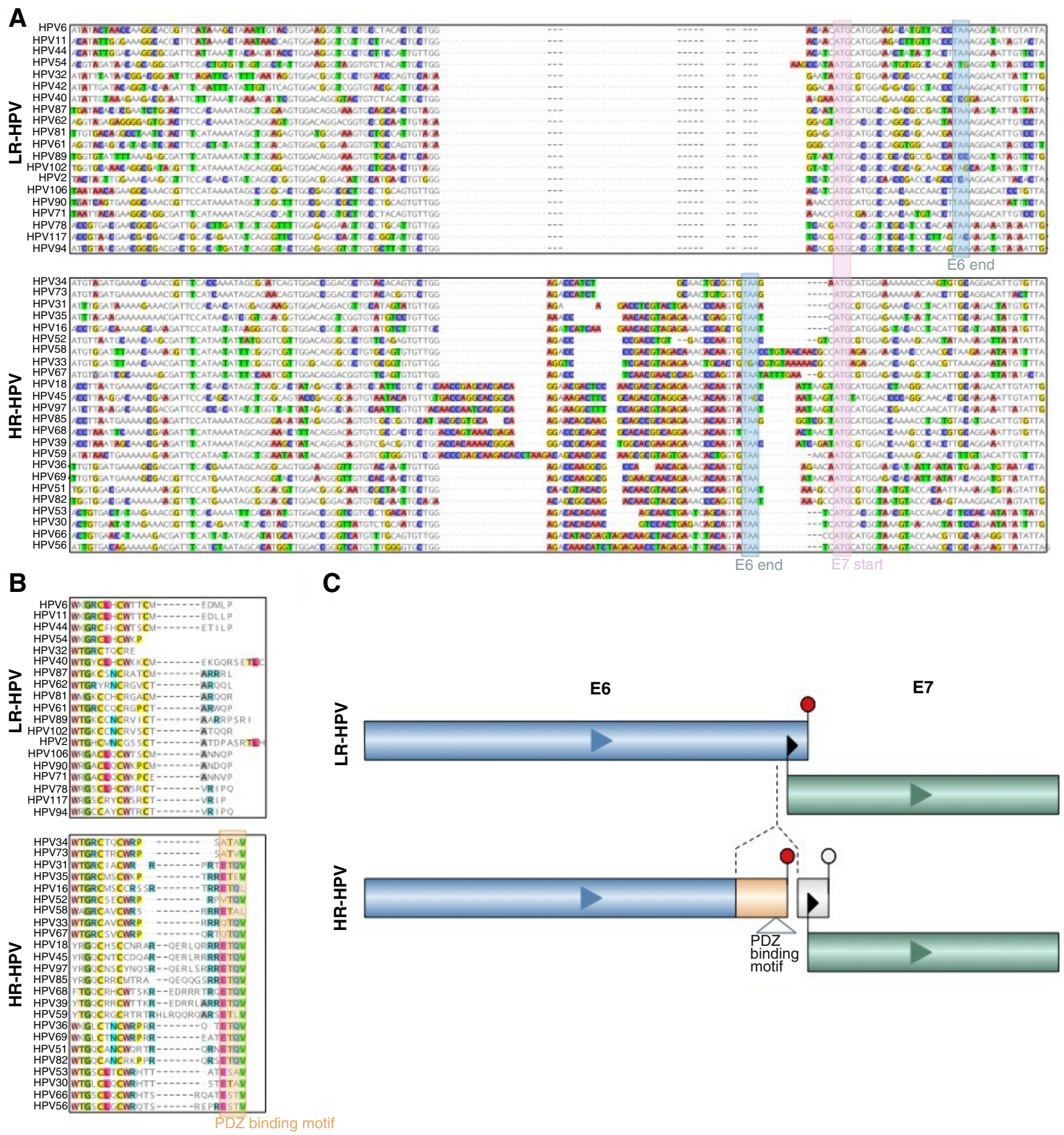

Figure 2. HR-HPV-specific sequence insert. (A) Nucleotide sequence alignment of alpha-HPVs (upper panel are LR-HPV and lower panel are HR-HPV sequences). Boxed sequences: pink box, E7 start codon for most HPV types; blue boxes, E6 stop codons that are distinct between HR-HPV and LR-HPV. (B) Amino acid sequence alignment of alpha-HPVs (upper panel are LR-HPV and lower panel are HR-HPV sequences). The orange box shows the PDZ-binding motifs in E6 of HR-HPV. (C) Schematic representation of the E6/E7 separation through the insertion in E6 and the proximity of E6 stop and E7 starts in HR-HPV. 


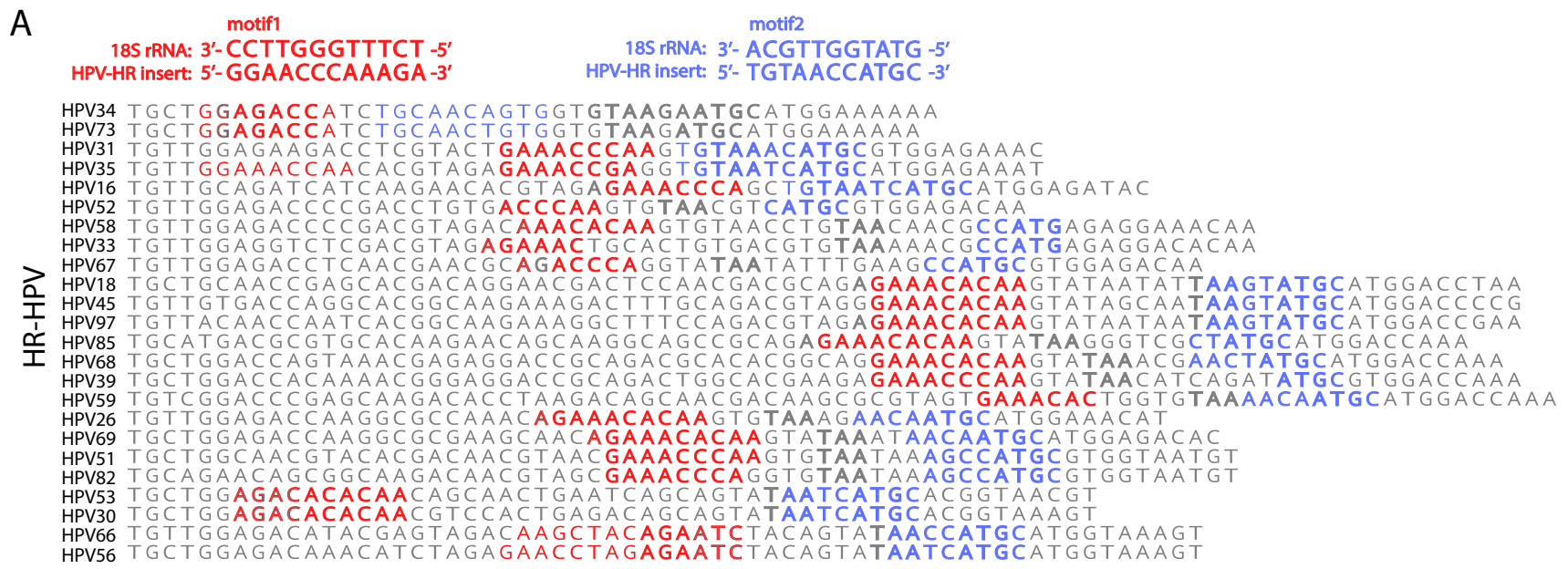

B

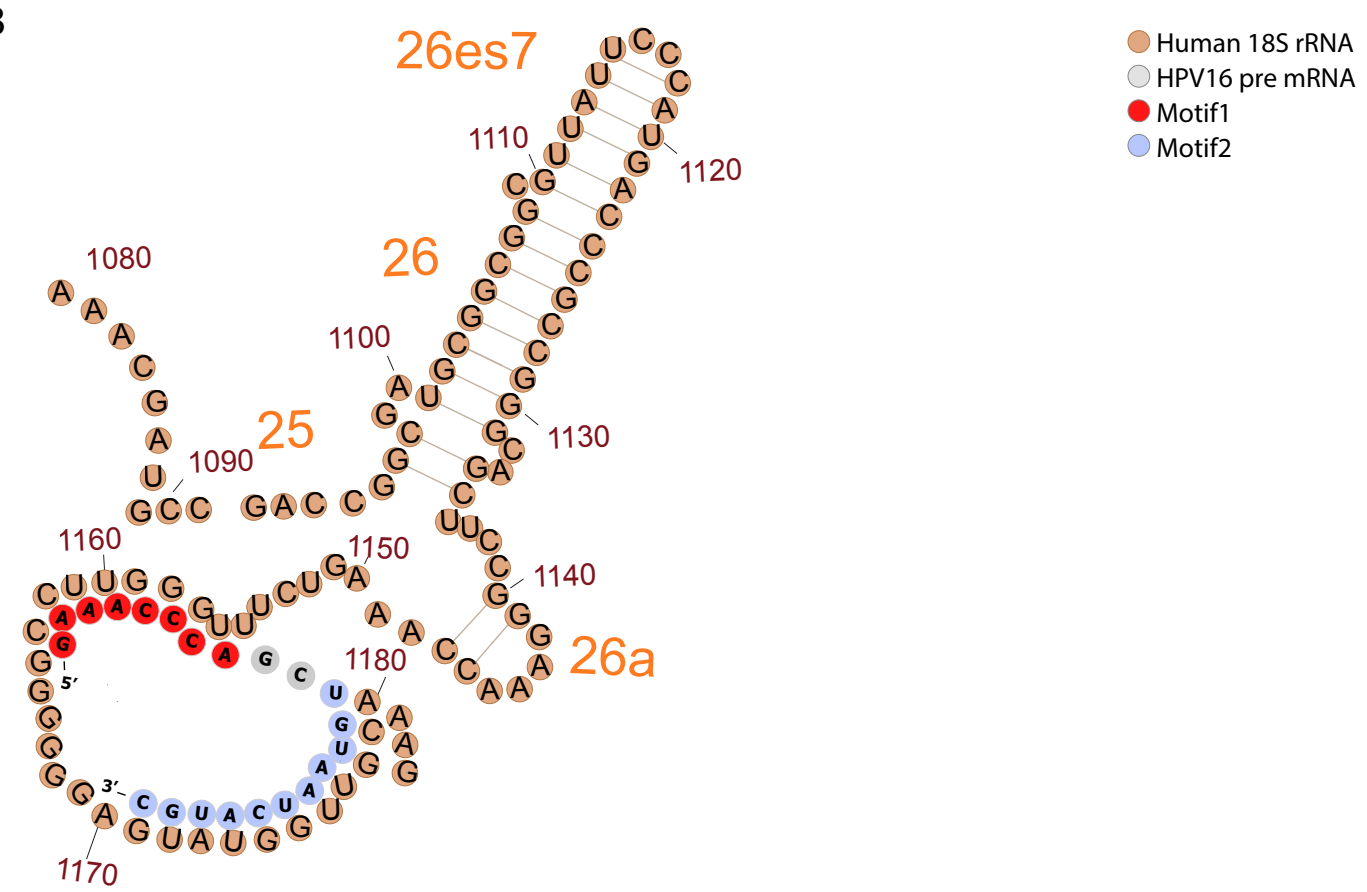

Figure 3. Sequences complementary to 18S rRNA sequence in the HR-HPV-specific insert. (A) Comparison of 18S rRNA complementary sequences for different HR-HPV strains. The distal and proximal to the E7 start motifs (motifs 1 and 2) to the E7 start codon are shown in red and blue, respectively. The E6 stop codons (TAA) and E7 start codons are marked in bold. (B) An illustration of the potential interactions between folded HPV16 pre-mRNA (grey, red and blue) and the human 18S rRNA (brown). The two motifs are marked on the HPV-structure in red (motif 1) and blue (motif 2).

foldings of HR-HPV strains ${ }^{54}$ (Extended data: Figure $\mathrm{S}^{31}$, see Methods). The second region of 18S RNA complementarity overlaps with the E7 start site, and hence might function independently in the re-initiation of E7 translation (Figure 3B). These findings suggest that the insertion could enable coupled termination-reinitiation of E6 and E7 proteins, enhancing their combined expression in HR-HPV, and thus promoting the oncogenic transformation induced by these viruses.

\section{Discussion}

The genus Alphapapillomavirus includes HPV types that are uniquely pathogenic. However, the events in the HPV genome evolution that led to the carcinogenic potential of some alphaHPV types remain poorly understood. Here, we revisited this problem by performing a search for genomic determinants of the oncogenic risk of alpha-HPV types and identified a unique insert in the 3'-terminal region of the E6 oncoprotein 
gene in all HR HPV strains. To the best of our knowledge, this insert in HR-HPV genomes has not been reported previously. The insertion maintains closely similar lengths of E6 proteins in HR-HPV and LR-HPV types, which could explain why it has been overlooked in previous HPV genome analyses.

We hypothesize that the insertion makes a dual contribution to the oncogenicity of the HR-HPV types. First, the inserted sequence changes the C-terminal amino acid sequence of E6 and creates a PDZ domain-binding motif that is unique to HR-HPV types. The experimentally demonstrated interaction between the E6 proteins of HR-HPV and several PDZ domain-containing proteins is thought to make a substantial contribution to HPVinduced tumorigenesis ${ }^{27,29,55}$. Interestingly, PDZ-binding motifs have been identified also in several other oncogenic viruses, such as HTLV-1, adenovirus RhPV1 and beta-HPV ${ }^{56,57}$. Second, the insert eliminates the overlap between the E6 and E7 coding regions, implying a possible role as a regulatory region. We find that almost all HR-HPV genomes contain the sequence T-A/G-T-A-A-T/A in the insert near the end of the E6 coding sequence, a closely similar sequence to that functioning as the early promoter at the 5' end of E6 and is employed for producing the mRNAs for both E6 and E7 ${ }^{58,59}$. However, in HR-HPV strains, unlike the case of the LR-HPV ${ }^{39}$, there are no reports of an independent E7 promoter, and E6 and E7 are both translated from a polycistronic mRNA.

Further investigating the potential regulatory role of the inserted sequence, we identified two conserved motifs that are complementary to the human $18 \mathrm{~S}$ rRNA; interaction of such motifs with the rRNA has been shown to play a role in coupled termination-reinitiation for several viral genes ${ }^{45,46,51,53}$. The first motif forms an internal loop in the predicted mRNA secondary structure of E6E7, whereas the second one overlaps with the E7 initiation codon. Given the evolutionary conservation of these motifs and the close proximity of E6 termination site to the E7 initiation site, it appears plausible that coupled termination-reinitiation promoted by the insert sequence is a central mechanism for E7 translation in HR-HPV strains. Given the lack of additional major genomic determinants that would consistently differentiate between HR-HPV and LR-HPV, it seems likely that the insert in E6 is the primary cause behind the emergence of oncogenic HPV.

\section{Methods}

Multiple sequence alignment and phylogenetic analysis

Multiple alignments of nucleotide and amino acid sequences that were obtained from GenBank (Extended data: Table S1 ${ }^{31}$ ) were generated using MAFFT v7.40760 with default parameters. Maximum likelihood phylogenetic analysis was performed using the resulting alignments and PhyML 3.1 software $^{61}$, with the Bayesian information criterion, NNI tree improvement and an LRT SH-like likelihood method for support estimation.

\section{SVM applied to nucleotide sequences}

To apply Support Vector Machines (SVM ${ }^{62}$, using Matlab 2018b fitsvm function) to the nucleotide sequences, we first encoded the data with numbers, where each nucleotide is coded as ' 1 ', and each gap as ' 0 '. We searched for alignment regions with deletions or insertions in multiple HPV strains that are surrounded by high confidence alignment regions (alignment regions of length $>15$ bp containing less than $5 \%$ of gaps in each position) because these are most likely to contain relevant differences within conserved genomic regions. Within these regions, we then trained the SVM to classify alpha-HPV strains based on their oncogenic potential. The performance of the SVM was evaluated by leave-one-out cross validation, and regions with the overall balanced accuracy $>0.75$ (the average of the accuracy for positive and negative classes) were selected for further analysis.

\section{SVM applied to amino acid sequences}

To apply SVM (using Matlab 2018b fitsvm function) to the amino acid sequences of E6 and E7 proteins, we first encoded the amino acids with numbers using the frequencies of each amino acid in each protein and the BLOSUM62 matrix ${ }^{32}$. For each position, the most frequent amino acid was identified, and the amino acids in each protein were encoded by their BLOSUM62 distances from the most frequent amino acid in the respective position. We then trained the SVM to classify alphaHPV strains based on their oncogenic potential using the coded protein sequences. Positions surrounded by high-confidence alignment regions (length $>5$ amino acids and containing less than $5 \%$ of gaps in each position) were selected for further analysis. For these positions, we evaluated the performance by leave-one-out cross validation, and regions with the overall balanced accuracy $>0.75$ were selected for further estimation of significance using a permutation test.

\section{Estimation of the significance of the identified regions using permutations}

To estimate the significance of the identified regions, i.e. to determine whether similar differences could be observed by chance, we performed a permutation test (Extended data ${ }^{63}$ ), controlling for the topology of the reconstructed phylogenetic trees. To this end, the labels were randomly permuted while maintaining unified labels for clades with high similarity. For each identified region, the likelihood of obtaining an equivalent or higher performance for the length of the region within the respective protein was evaluated by calculating an empirical P-value. We consider regions with permutation $\mathrm{P}$-value $<0.05$.

\section{Analysis of RNA folding and RNA-RNA duplexes}

The most stable secondary structures were predicted for all HR-HPV strains and their free energy values were calculated using the Vienna package ${ }^{54}$. Afold and Mfold were applied for prediction of optimal and sub-optimal mRNA structures ${ }^{64,65}$. Target opening free energy was estimated for motifs 1 and 2 using optimal and sub-optimal RNA structures, as described previously ${ }^{66}$. The sequence fold variants with the lowest secondary-structure free energy are presented in the Extended data: Figure $\mathrm{S}^{31}$. The formation of intermolecular mRNArRNA duplexes and hybridization affinity of the E6-E7 inserts to ribosomal RNA were evaluated using the Hybrid software with default parameters, with a $\Delta \mathrm{G}$ threshold of $\leq-10 \mathrm{kcal} / \mathrm{mol}^{67}$. The human 18S rRNA 2D structure was extracted from the 
structures of X-ray structure of eukaryotic ribosome (http:// apollo.chemistry.gatech.edu/RibosomeGallery/H\%20sapiens/ SSU/index.html; 68,69).

\section{Data availability}

\section{Underlying data}

Nucleotide sequences of HPV and amino acid sequences of HPV E6 and E7 proteins are available as extended data.

\section{Extended data}

Harvard Dataverse: A unique insert in the genomes of in highrisk human papillomaviruses with a predicted dual role in conferring oncogenic risk, https://doi.org/10.7910/DVN/ FUGEUB $^{31}$

This project contains the following extended data:

- Table 1: Complete nucleotide sequences and the amino acid sequences of HPV E1, E2, E4, E5, E6, E7, L1 and $\mathrm{L} 2$ proteins. This is the only source data that was required and employed for the analysis reported in this work.

- Figure S1: Maximum likelihood trees obtained with alignments of E6, E7, E1, E2, E4, E5, L1 and L2 amino acid sequences of alpha-HPV strains.

- Figure S2: The balanced accuracy (y-axis) obtained from a leave-one-out cross validation for predicting risk category (HR vs LR) of alpha-HPV strains using BLOSUM62 coding of amino acid sequences, of different positions (x-axis) E6 (A) and E7 (B). Zeroaccuracy was assigned to regions surrounded with low confidence alignment.

- Figure S3: Boxplots showing the distributions of the identity fraction of each nucleotide (NN) and amino acid (AA) in the genome and protein sequences of the insertion (not considering gaps for both $\mathrm{NN}$ and $\mathrm{AA}$ ). The individual identity fractions of each position are overlaid.

- Figure S4: RNA fold secondary structure prediction of HR HPV strains 16 (A), 18 (B), 45 (C) and 31 (D). The nucleotides of the first motif are marked in red, and of the second motif in purple. E7 AUG is noted in red font.

Data are available under the terms of the Creative Commons Zero "No rights reserved" data waiver (CC0 1.0 Public domain dedication)

Zenodo: Permutation test controlling for HPV strains, http://doi. org/10.5281/zenodo.324223163. Apache License, Version 2.0.

Grant information

This work was supported by U.S. Department of Health and Human Services (Intramural funds).

The funders had no role in the study design, data collection, analysis, decision to publish, or preparation of the manuscript.
1. Walboomers JM, Jacobs MV, Manos MM, et al.: Human papillomavirus is a necessary cause of invasive cervical cancer worldwide. J Pathol. 1999; 189(1): $12-9$

PubMed Abstract | Publisher Full Text

2. Bosch FX, de Sanjosé S: Chapter 1: Human papillomavirus and cervica cancer--burden and assessment of causality. J Natl Cancer Inst Monogr. 2003; 2003(31): 3-13.

PubMed Abstract | Publisher Full Text

3. Bosch FX, Lorincz A, Muñoz N, et al:: The causal relation between human papillomavirus and cervical cancer. J Clin Pathol. 2002; 55(4): 244-65. PubMed Abstract | Free Full Text

4. de Villiers EM: Cross-roads in the classification of papillomaviruses. Virology. 2013; 445(1-2): 2-10.

PubMed Abstract | Publisher Full Text

5. Bernard HU, Burk RD, Chen Z, et al.: Classification of papillomaviruses (PVs) based on $189 \mathrm{PV}$ types and proposal of taxonomic amendments. Virology. 2010; 401(1): 70-9

PubMed Abstract | Publisher Full Text | Free Full Text

6. de Villiers EM, Fauquet C, Broker TR, et al:: Classification of papillomaviruses. Virology. 2004; 324(1): 17-27.

PubMed Abstract | Publisher Full Text

7. Muñoz N, Bosch FX, de Sanjosé S, et al.: Epidemiologic classification of human papillomavirus types associated with cervical cancer. N Engl J Med. 2003; 348(6): 518-27.

PubMed Abstract | Publisher Full Text

8. Smith JS, Lindsay L, Hoots $B$, et al: Human papillomavirus type distribution in invasive cervical cancer and high-grade cervical lesions: a meta-analysis update. Int J Cancer. 2007; 121(3): 621-32.

PubMed Abstract | Publisher Full Text

9. Schiffman M, Herrero R, Desalle R, et al.: The carcinogenicity of human papillomavirus types reflects viral evolution. Virology. 2005; 337(1): 76-84. PubMed Abstract | Publisher Full Text

10. Narechania A, Chen Z, DeSalle R, et al.: Phylogenetic incongruence among oncogenic genital alpha human papillomaviruses. J Virol. 2005; 79(24): 15503-10.

PubMed Abstract | Publisher Full Text | Free Full Text

11. García-Vallvé S, Alonso A, Bravo IG: Papillomaviruses: different genes have different histories. Trends Microbiol. 2005; 13(11): 514-21. PubMed Abstract | Publisher Full Text

12. McLaughlin-Drubin ME, Münger K: Oncogenic activities of human papillomaviruses. Virus Res. 2009; 143(2): 195-208. PubMed Abstract | Publisher Full Text | Free Full Text

13. Ghittoni $R$, Accardi $R$, Hasan $U$, et al:: The biological properties of $E 6$ and $E 7$ oncoproteins from human papillomaviruses. Virus Genes. 2010; 40(1): 1-13. PubMed Abstract | Publisher Full Text

14. Münger K, Howley $P$, Di Maio D: Human papillomavirus E6 and E7 oncogenes. In: The Papillomaviruses. 2007; 197-252. Publisher Full Text

15. Moody CA, Laimins LA: Human papillomavirus oncoproteins: pathways to transformation. Nat Rev Cancer. 2010; 10(8): 550-60. PubMed Abstract | Publisher Full Text

16. Yim EK, Park JS: The role of HPV E6 and E7 oncoproteins in HPV-associated cervical carcinogenesis. Cancer Res Treat. 2005; 37(6): 319-24. PubMed Abstract | Publisher Full Text | Free Full Text

17. Münger K, Scheffner M, Huibregtse JM, et al.: Interactions of HPV E6 and E7 oncoproteins with tumour suppressor gene products. Cancer Surv. 1992; 12: 197-217. PubMed Abstract

18. Barbosa MS, Vass WC, Lowy DR, et al:: In vitro biological activities of the E6 and E7 genes vary among human papillomaviruses of different oncogenic 
potential. J Virol. 1991; 65(1): 292-8. PubMed Abstract | Free Full Text

19. Halbert CL, Demers GW, Galloway DA: The E6 and E7 genes of human papillomavirus type 6 have weak immortalizing activity in human epithelial cells. J Virol. 1992; 66(4): 2125-34. PubMed Abstract | Free Full Text

20. Thomas M, Banks L: Human papillomavirus (HPV) E6 interactions with Bak are conserved amongst $\mathrm{E} 6$ proteins from high and low risk HPV types. $J$ Gen Virol. 1999; 80(Pt 6): 1513-7.

PubMed Abstract | Publisher Full Text

21. Schmitt A, Harry JB, Rapp B, et al.: Comparison of the Properties of the E6 and E7 Genes of Low- and High-Risk Cutaneous Papillomaviruses Reveals Strongly Transforming and High Rb-Binding Activity for the E7 Protein of the Low-Risk Human Papillomavirus Type 1. J Virol. 1994; 68(11): 7051-9. PubMed Abstract | Free Full Text

22. Zhang B, Chen W, Roman A: The E7 proteins of low- and high-risk human papillomaviruses share the ability to target the pRB family member $p 130$ fo degradation. Proc Natl Acad Sci U S A. 2006; 103(2): 437-42. PubMed Abstract | Publisher Full Text | Free Full Text

23. Ciccolini F, Di Pasquale G, Carlotti F, et al:: Functional studies of E7 proteins from different HPV types. Oncogene. 1994; 9(9): 2633-8. PubMed Abstract

24. Band V, Dalal S, Delmolino L, et al.: Enhanced degradation of $p 53$ protein in HPV-6 and BPV-1 E6-immortalized human mammary epithelial cells. EMBO J. 1993; 12(5): 1847-52.

PubMed Abstract | Publisher Full Text | Free Full Text

25. Thomas M, Narayan N, Pim D, et al:: Human papillomaviruses, cervical cancer and cell polarity. Oncogene. 2008; 27(55): 7018-30. PubMed Abstract | Publisher Full Text

26. Glaunsinger BA, Lee SS, Thomas M, et al:: Interactions of the PDZ-protein MAGI1 with adenovirus E4-ORF1 and high-risk papillomavirus E6 oncoproteins. Oncogene. 2000; 19(46): 5270-80.

PubMed Abstract | Publisher Full Text | Free Full Text

27. Nguyen ML, Nguyen MM, Lee D, et al:: The PDZ ligand domain of the human papillomavirus type 16 E6 protein is required for E6's induction of epithelia hyperplasia in vivo. $J$ Virol. 2003; 77(12): 6957-64 PubMed Abstract | Publisher Full Text | Free Full Text

28. Pim D, Bergant M, Boon SS, et al.: Human papillomaviruses and the specificity of PDZ domain targeting. FEBS J. 2012; 279(19): 3530-7. PubMed Abstract | Publisher Full Text

29. Lee SS, Weiss RS, Javier RT: Binding of human virus oncoproteins to hDlg/ SAP97, a mammalian homolog of the Drosophila discs large tumor suppressor protein. Proc Natl Acad Sci U S A. 1997; 94(13): 6670-5. PubMed Abstract | Publisher Full Text | Free Full Text

30. Kiyono T, Hiraiwa A, Fujita M, et al:: Binding of high-risk human papillomavirus E6 oncoproteins to the human homologue of the Drosophila discs large tumo suppressor protein. Proc Natl Acad Sci U S A. 1997; 94(21): 11612-6. PubMed Abstract | Publisher Full Text | Free Full Text

31. Auslander $\mathrm{N}$ : $\mathbf{A}$ unique insert in the genomes of in high-risk human papillomaviruses with a predicted dual role in conferring oncogenic risk. Harvard Dataverse, V1, UNF:6:xr7J2/tBlpkOW0NJ2yoqLA== [fileUNF], 2019. http://www.doi.org/10.7910/DVN/FUGEUB

32. Henikoff $S$, Henikoff JG: Amino acid substitution matrices from protein blocks. Proc Natl Acad Sci U S A. 1992; 89(22): 10915-9. PubMed Abstract | Publisher Full Text | Free Full Text

33. Nakagawa S, Huibregtse JM: Human scribble (Vartul) is targeted for ubiquitinmediated degradation by the high-risk papillomavirus E6 proteins and the E6AP ubiquitin-protein ligase. Mol Cell Biol. 2000; 20(21): 8244-53. PubMed Abstract | Publisher Full Text | Free Full Text

34. Thomas M, Laura R, Hepner K, et al.: Oncogenic human papillomavirus E6 proteins target the MAGI-2 and MAGI-3 proteins for degradation. Oncogene. 2002; 21(33): 5088-96. PubMed Abstract | Publisher Full Text

35. Lee SS, Glaunsinger B, Mantovani F, et al:: Multi-PDZ domain protein MUPP1 is a cellular target for both adenovirus E4-ORF1 and high-risk papillomavirus type 18 E6 oncoproteins. J Virol. 2000; 74(20): 9680-93. PubMed Abstract | Publisher Full Text | Free Full Text

36. Lee C, Laimins LA: Role of the PDZ domain-binding motif of the oncoprotein E6 in the pathogenesis of human papillomavirus type 31. J Virol. 2004; 78(22): 12366-77.

PubMed Abstract | Publisher Full Text | Free Full Text

37. Riley RR, Duensing S, Brake $\mathrm{T}$, et al:: Dissection of human papillomavirus E6 and $E 7$ function in transgenic mouse models of cervical carcinogenesis. Cancer Res. 2003; 63(16): 4862-71.

PubMed Abstract

38. Zheng ZM, Baker CC: Papillomavirus genome structure, expression, and posttranscriptional regulation. Front Biosci. 2006; 11: 2286-302.

PubMed Abstract | Publisher Full Text | Free Full Text

39. Smotkin D, Prokoph H, Wettstein FO: Oncogenic and nononcogenic human genital papillomaviruses generate the E7 mRNA by different mechanisms. $J$ Virol. 1989; 63(3): 1441-7.

PubMed Abstract | Free Full Text

40. Tan TM, Gloss B, Bernard HU, et al:: Mechanism of translation of the bicistronic
mRNA encoding human papillomavirus type 16 E6-E7 genes. J Gen Virol. 1994; 75(Pt 10): 2663-70.

PubMed Abstract | Publisher Full Text

41. Tang S, Tao M, McCoy JP Jr, et al.: The E7 oncoprotein is translated from spliced E6*I transcripts in high-risk human papillomavirus type 16- or type 18-positive cervical cancer cell lines via translation reinitiation. J Virol. 2006; 80(9): 4249-63.

PubMed Abstract | Publisher Full Text | Free Full Text

42. Stacey SN, Jordan D, Snijders PJ, et al.: Translation of the human papillomavirus type $16 \mathrm{E7}$ oncoprotein from bicistronic mRNA is independent of splicing events within the E6 open reading frame. J Virol. 1995; 69(11): 7023-31.

PubMed Abstract | Free Full Text

43. del Moral-Hernández O, López-Urrutia E, Bonilla-Moreno R, et al.: The HPV-16 E7 oncoprotein is expressed mainly from the unspliced E6/E7 transcript in cervical carcinoma C33-A cells. Arch Virol. 2010; 155(12): 1959-70.

PubMed Abstract | Publisher Full Text

44. Pöyry TA, Kaminski A, Connell EJ, et al.: The mechanism of an exceptional case of reinitiation after translation of a long ORF reveals why such events do not generally occur in mammalian mRNA translation. Genes Dev. 2007; 21(23): 3149-62.

PubMed Abstract | Publisher Full Text | Free Full Text

45. Luttermann C, Meyers G: The importance of inter- and intramolecular base pairing for translation reinitiation on a eukaryotic bicistronic mRNA. Genes Dev. 2009; 23(3): 331-4.

PubMed Abstract | Publisher Full Text | Free Full Text

46. Powell ML, Napthine S, Jackson RJ, et al:: Characterization of the terminationreinitiation strategy employed in the expression of influenza $B$ virus BM2 protein. RNA. 2008; 14(11): 2394-406.

PubMed Abstract | Publisher Full Text | Free Full Text

47. Horvath CM, Williams MA, Lamb RA: Eukaryotic coupled translation of tandem cistrons: identification of the influenza B virus BM2 polypeptide. EMBO J. 1990; 9(8): 2639-47.

PubMed Abstract | Publisher Full Text | Free Full Text

48. Ahmadian G, Randhawa JS, Easton AJ: Expression of the ORF-2 protein of the human respiratory syncytial virus $M 2$ gene is initiated by a ribosomal termination-dependent reinitiation mechanism. EMBO J. 2002; 19(11): 2681-9. PubMed Abstract | Publisher Full Text | Free Full Text

49. Gould PS, Easton AJ: Coupled translation of the second open reading frame of M2 mRNA is sequence dependent and differs significantly within the subfamily Pneumovirinae. J Virol. 2007; 81(16): 8488-96. PubMed Abstract | Publisher Full Text | Free Full Text

50. Meyers G: Translation of the minor capsid protein of a calicivirus is initiated by a novel termination-dependent reinitiation mechanism. J Biol Chem. 2003; 278(36): 34051-60.

PubMed Abstract | Publisher Full Text

51. Luttermann C, Meyers G: A bipartite sequence motif induces translation reinitiation in feline calicivirus RNA. J Biol Chem. 2007; 282(10): 7056-65. PubMed Abstract | Publisher Full Text

52. Meyers G: Characterization of the sequence element directing translation reinitiation in RNA of the calicivirus rabbit hemorrhagic disease virus. $J$ Virol. 2007; 81(18): 9623-32.

PubMed Abstract | Publisher Full Text | Free Full Tex

53. Powell ML, Brown TD, Brierley I: Translational termination-re-initiation in viral systems. Biochem Soc Trans. 2008; 36(Pt 4): 717-22. PubMed Abstract | Publisher Full Text

54. Lorenz R, Bernhart SH, Höner zu Siederdissen C, et al:: ViennaRNA Package 2.0 Algorithms Mol Biol. 2011; 6(1): 26. PubMed Abstract | Publisher Full Text | Free Full Text

55. Watson RA, Thomas M, Banks L, et al:: Activity of the human papillomavirus E6 PDZ-binding motif correlates with an enhanced morphological transformation of immortalized human keratinocytes. J Cell Sci. 2003; 116(Pt 24): 4925-34. PubMed Abstract | Publisher Full Text

56. James CD, Roberts S: Viral Interactions with PDZ Domain-Containing ProteinsAn Oncogenic Trait? Pathogens. 2016; 5(1): pii: E8. PubMed Abstract | Publisher Full Text | Free Full Text

57. Javier RT, Rice AP: Emerging theme: cellular PDZ proteins as common targets of pathogenic viruses. J Virol. 2011; 85(22): 11544-56. PubMed Abstract | Publisher Full Text | Free Full Text

58. Thierry F: Transcriptional regulation of the papillomavirus oncogenes by cellular and viral transcription factors in cervical carcinoma. Virology. 2009 384(2): 375-9.

PubMed Abstract | Publisher Full Text

59. Gloss B, Bernard HU: The E6/E7 promoter of human papillomavirus type 16 is activated in the absence of E2 proteins by a sequence-aberrant Sp1 distal element. J Virol. 1990; 64(11): 5577-84. PubMed Abstract | Free Full Text

60. Katoh K, Misawa K, Kuma K, et al:: MAFFT: a novel method for rapid multiple sequence alignment based on fast Fourier transform. Nucleic Acids Res. 2002 30(14): 3059-66.

PubMed Abstract | Publisher Full Text | Free Full Text

61. Guindon S, Lethiec F, Duroux P, et al:: PHYML Online--a web server for fast maximum likelihood-based phylogenetic inference. Nucleic Acids Res. 2005; 
33(Web Server issue): W557-9.

PubMed Abstract | Publisher Full Text | Free Full Text

62. Cortes C, Vapnik V: Support-Vector Networks. Mach Learn. 1995; 20(3): 273-97. Publisher Full Text

63. Auslander N, Wolf IY, Shabalina AS, et al.: Permutation test controlling for HPV strains. Zenodo. 2019.

http://www.doi.org/10.5281/zenodo.3242231

64. Ogurtsov AY, Shabalina SA, Kondrashov AS, et al:: Analysis of internal loops within the RNA secondary structure in almost quadratic time. Bioinformatics. 2006; 22(11): 1317-24.

PubMed Abstract | Publisher Full Text

65. Mathews DH, Turner DH, Zuker M: RNA secondary structure prediction. Curr Protoc Nucleic Acid Chem. 2007; Chapter 11: Unit 11.2. PubMed Abstract | Publisher Full Text | Free Full Text
66. Faure G, Ogurtsov AY, Shabalina SA, et al.: Role of mRNA structure in the control of protein folding. Nucleic Acids Res. 2016; 44(22): 10898-10911. PubMed Abstract | Publisher Full Text | Free Full Text

67. Matveeva OV, Shabalina SA: Intermolecular mRNA-rRNA hybridization and the distribution of potential interaction regions in murine 18S rRNA. Nucleic Acids Res. 1993; 21(4): 1007-11.

PubMed Abstract | Publisher Full Text | Free Full Text

68. Ogurtsov AY, Mariño-Ramírez L, Johnson GR, et al.: Expression patterns of protein kinases correlate with gene architecture and evolutionary rates. PLOS One. 2008; 3(10): e3599.

PubMed Abstract | Publisher Full Text | Free Full Text

69. Melnikov S, Ben-Shem A, Garreau de Loubresse N, et al:: One core, two shells: bacterial and eukaryotic ribosomes. Nat Struct Mol Biol. 2012; 19(6): 560-7. PubMed Abstract | Publisher Full Text 


\section{Open Peer Review}

\section{Current Peer Review Status:}

\section{Version 1}

Reviewer Report 06 August 2019

https://doi.org/10.5256/f1000research.21480.r51570

(C) 2019 White E. This is an open access peer review report distributed under the terms of the Creative Commons Attribution License, which permits unrestricted use, distribution, and reproduction in any medium, provided the original work is properly cited.

\section{Elizabeth A. White}

Department of Otorhinolaryngology: Head and Neck Surgery, University of Pennsylvania Perelman School of Medicine, Philadelphia, USA

In this study, Auslander and colleagues compare nucleotide and amino acid sequences for a subset of genus alpha HPV genotypes. They observe that high-risk HPV genomes share a short sequence insert at the $3^{\prime}$ end of the E6 ORF. The insertion adds a PDZ binding motif to the Cterminus of high-risk HPV E6 proteins and alters the location of the E6 termination codon relative to the E7 initiation codon.

This observation is consistent with previous findings. It has been appreciated for some time that high-risk HPV E6 and E7 are transcribed from a polycistronic mRNA whereas low-risk E6 and E7 are transcribed from separate promoters. In addition, a frequent splicing event occurs within the E6 gene in the bicistronic high-risk HPV early mRNA. This report adds to those observations. It proposes that the $3^{\prime}$ high-risk specific insert is another feature that differs between high- and lowrisk HPV and that it might drive differences in expression of high-risk versus low-risk HPV oncoproteins. Understanding the differences between oncogenic and non-oncogenic HPV is an area of intensive research and new contributions in this area are potentially significant. This report makes a useful contribution to the literature.

Weaknesses of the manuscript are that the current literature is not cited and that other features of high-risk HPV E6 that might also account for their oncogenic activities are not discussed. Although comparing nucleotide sequence differences is informative, for HPV E6 this comparison does not completely reflect the biology of the proteins. There are high-risk HPV E6-specific protein binding partners other than PDZ domain proteins. Several of these are listed in a useful 2012 review ${ }^{1}$; others were identified by proteomic analyses from several groups ${ }^{23}$. For example, the authors do not mention that TP53 binding and degradation is a feature of high-risk HPV E6 not shared by lowrisk HPV E6. It also appears that not all of the high-risk HPV E6 interact with the same subset of cellular PDZ proteins. It is unclear how these diverse HPV E6-PDZ protein interactions might account for the shared oncogenic features of high-risk HPV E6, and this point is not discussed in the manuscript. 
It is established in the HPV literature that small differences in HPV oncoprotein amino acid sequence result in significant differences in interactions with host cellular proteins. This is beautifully illustrated by the structural studies of Gilles Trave and colleagues, who have determined that subtle differences in E6 enable a range of specific interactions with cellular LxxLLcontaining proteins. Other recent studies highlight high-risk HPV-specific activities of the E7 oncoprotein. In light of findings like these, this manuscript seems to overstate the claim that the PDZ binding motif is the 'most notable molecular feature' distinguishing high- from low-risk HPV. The potential importance of the insert sequence to E6/E7 translation regulation is high and should be tested; the discussion of the importance of the PDZ binding motif should be tempered and put in context with other recent findings.

Additional points:

1. Mirabello and colleagues recently reported an analysis of sequence variants from $>5000$ HPV16-positive cervical samples ${ }^{4}$. HPV16 E6 sequences exhibited variation across the length of the ORF that was similar in high-grade versus control lesions. A possible interpretation of this finding is that the protein sequence in the C-terminus of E6 is not important for oncogenic transformation. How does this fit into the authors' model? It would be useful to include a discussion of these data.

2. The phylogenetic trees in Figure 1B might be easier to interpret if they were presented in a linear format. It is difficult to determine where the boundaries between the high-risk/lowrisk groupings overlap with the major branch points of the tree.

3. HPV diversity is much greater that that reflected solely in genus alpha. It would be interesting to know whether HPV from other genera have also acquired sequences in this region that might provide some or all of the activities suggested by the authors.

\section{References}

1. Klingelhutz AJ, Roman A: Cellular transformation by human papillomaviruses: lessons learned by comparing high- and low-risk viruses.Virology. 2012; 424 (2): 77-98 PubMed Abstract | Publisher Full Text

2. Rozenblatt-Rosen O, Deo RC, Padi M, Adelmant G, et al.: Interpreting cancer genomes using systematic host network perturbations by tumour virus proteins.Nature. 2012; 487 (7408): 491-5 PubMed Abstract | Publisher Full Text

3. White EA, Kramer RE, Tan MJ, Hayes SD, et al.: Comprehensive analysis of host cellular interactions with human papillomavirus E6 proteins identifies new E6 binding partners and reflects viral diversity.J Virol. 2012; 86 (24): 13174-86 PubMed Abstract | Publisher Full Text 4. Mirabello L, Yeager M, Yu K, Clifford GM, et al.: HPV16 E7 Genetic Conservation Is Critical to Carcinogenesis.Cell. 2017; 170 (6): 1164-1174.e6 PubMed Abstract | Publisher Full Text

Is the work clearly and accurately presented and does it cite the current literature? Partly

Is the study design appropriate and is the work technically sound? Yes

Are sufficient details of methods and analysis provided to allow replication by others? 
Yes

If applicable, is the statistical analysis and its interpretation appropriate?

I cannot comment. A qualified statistician is required.

Are all the source data underlying the results available to ensure full reproducibility? Yes

Are the conclusions drawn adequately supported by the results?

Partly

Competing Interests: No competing interests were disclosed.

Reviewer Expertise: HPV E6 and E7, protein-protein interactions, transformation

I confirm that I have read this submission and believe that I have an appropriate level of expertise to confirm that it is of an acceptable scientific standard.

Author Response ( F1000Research Advisory Board Member) 13 Sep 2019

Eugene Koonin, National Institutes of Health, USA, Bethesda, USA

We appreciate this highly constructive and helpful review in response to which the following modifications have been made too the article:

1. Many references to the current literature were added, and several other features of HR-HPV E6 are now discussed.

2. The suggested references to HR-HPV E6 specific binding partners have been included.

3. The discussion on the importance of the PDZ binding motif in distinguishing HR from LR HPV has been tempered, and the context for its potential relevance has been clarified.

4. We now discuss the recent analysis of 5570 cervical HPV16 genomes (Mirabello and colleagues) and have substantially expanded the discussion of the effect of the insert on E7 production.

5. Figure $1 \mathrm{~B}$ has been updated, phylogenetic trees are now presented in a linear format.

In addition, although the referee have suggested a statistical review of the permutation test that was used in this work to assess the significance of the results, we are confident that this is unnecessary because the statistical technique we used is simple and standard.

Competing Interests: I declare no competing interests 
Reviewer Report 31 July 2019

https://doi.org/10.5256/f1000research.21480.r51173

(c) 2019 McBride A. This is an open access peer review report distributed under the terms of the Creative Commons Attribution License, which permits unrestricted use, distribution, and reproduction in any medium, provided the original work is properly cited. The author(s) is/are employees of the US Government and therefore domestic copyright protection in USA does not apply to this work. The work may be protected under the copyright laws of other jurisdictions when used in those jurisdictions.

\author{
Alison McBride \\ DNA Tumor Virus Section, National Institute of Allergy and Infectious Diseases (NIAID), Bethesda, \\ MD, USA
}

Auslander and colleagues present a comparative sequence analysis of alpha-papillomavirus genomes. They identify and analyze a short 30-60 nucleotide sequence insert between the E6 and E7 open-reading frames that encodes the PDZ domain in the high-oncogenic risk types and propose that this region also contains sequences that enable coupled termination and reinitiation to facilitate translation of the E6 and E7 proteins. This is an intriguing observation as HPVs are associated with $\sim 5 \%$ human cancers and understanding how the viral oncoproteins are expressed is crucial. The proposed hypothesis should be testable and indicates that experiments in which the E6 PDZ domain is mutated in the background of the viral genome should be interpreted carefully.

A weakness of the manuscript is that current literature and data sources are not used/and or cited and the data-set used seems incomplete. For example, there are currently 198 officially numbered HPV types, and 442 HPV types in total. A curated data-set of genome sequences for all papillomavirus types sequenced to date is available at PaVE. There are also many recent publications that describe analyses of PV evolution, oncogenicity and E6 PDZ domains that should be cited.

There are sequences available for 64 alpha HPV types that have been officially named by the HPV Reference Centre, yet only the genomic sequences of 44 types are listed in Figure $\mathrm{S1}$. The data-set contains many isolates for some HPV types (e.g. 299 isolates of HPV16) yet almost no representatives of the species alpha 2, 4 and 8. The E6 protein of HPV40 (alpha-8) has been proposed to contain an ancestral alpha PDZ domain and so the genomes of the alpha- 8 species should be closely examined/discussed. Nevertheless, a nucleotide alignment of all 64 alpha-PV nucleotide sequences from PaVE does support the authors' conclusions that only HR species-5, 67 , 9 and 11 contain an insert separating the E6 and E7 ORFs.

\title{
Minor issues:
}

1. In Figure $1 \mathrm{~A}$, alpha-11 is listed in the key for both $L R$ and HR.

2. In Figure 2, the resolution of the sequence images should be improved. The legend for $2 B$ should make it clear that these are just the C-terminal sequences of the E6 polypeptides. In $2 \mathrm{C}$, the symbols and colored blocks should be described.

3. In Figure $3 A$, the color/bold identification of the motifs and TAA/AUG are not easily 
visualized in the pdf. Perhaps highlight TAA/AUG by underlines or boxes. Labelling the groups of different HPV species along the left would also be helpful. In 3B, the labelling of the $18 \mathrm{~S}$ rRNA hairpin (orange text) is confusing. What is $26 \mathrm{es} 7$ ?

4. In Figure S4: clarify in the legend that this is the E6-E7 RNA sequence for each HPV type shown.

5. The reference for IRES (54), I think should be 53.

Is the work clearly and accurately presented and does it cite the current literature? Partly

Is the study design appropriate and is the work technically sound?

Yes

Are sufficient details of methods and analysis provided to allow replication by others? Yes

If applicable, is the statistical analysis and its interpretation appropriate?

I cannot comment. A qualified statistician is required.

Are all the source data underlying the results available to ensure full reproducibility? Yes

Are the conclusions drawn adequately supported by the results? Yes

Competing Interests: I founded and oversee the NIAID papillomavirus bioinformatics site https://pave.niaid.nih.gov/ described in the review

Reviewer Expertise: HPV replication, genomics, epigenetics

I confirm that I have read this submission and believe that I have an appropriate level of expertise to confirm that it is of an acceptable scientific standard.

Author Response ( F1000Research Advisory Board Member ) 13 Sep 2019

Eugene Koonin, National Institutes of Health, USA, Bethesda, USA

We appreciate the constructive and very helpful review in response to which the following changes have been made to the manuscript:

1. We now mention the most recent number of HPV types that have been formally recognized (198), and the reference supporting this has been updated.

2. We added numerous references to recent publications that describe analyses of HPV evolution, oncogenicity, oncoprotein interactions and E6 interactions with PDZ 
domains.

3. We now include all 64 alpha HPV types from PaVE, and all analyses and figures 1-3 include those HPV strains.

4. Resolution of the new figures has been improved.

5. The legend to Figure $2 \mathrm{~B}$ has been modified as suggested.

6. The legend to Figure $2 \mathrm{C}$ describes all symbols and colored blocks.

7. Figure $3 \mathrm{~A}$ has been updated to show the motifs clearly and arrange the strains by the order in the phylogenetic tree.

8. Figure 3B has been updated, confusing labelling of 18S rRNA removed.

Competing Interests: I declare no competing interests.

\section{Author Response ( F1000Research Advisory Board Member) 13 Sep 2019}

Eugene Koonin, National Institutes of Health, USA, Bethesda, USA

Although the referee has suggested a statistical review of the permutation test that was used in this work to assess the significance of the results, we are confident that this is unnecessary because the statistical technique we used is simple and standard.

Competing Interests: I declare no competing interests. 
The benefits of publishing with F1000Research:

- Your article is published within days, with no editorial bias

- You can publish traditional articles, null/negative results, case reports, data notes and more

- The peer review process is transparent and collaborative

- Your article is indexed in PubMed after passing peer review

- Dedicated customer support at every stage

For pre-submission enquiries, contact research@f1000.com 